\section{Commentary: Uncrossing the right to make it right!}

\author{
Awais Ashfaq, MD, and \\ David Winlaw, MBBS, MD, FRACS
}

The aortic uncrossing procedure, first reported by Planché and Lacour-Gayet, ${ }^{1}$ addresses a "circumflex aorta," the combination of a right aortic arch with a left ligamentum arteriosum and a descending thoracic aorta that crosses posteriorly from right to left above the level of the tracheal carina. It is generally performed through a median sternotomy with cardiopulmonary bypass and moderate-to-deep hypothermia and short period of circulatory arrest. ${ }^{2}$

In the current case depicted by Said and colleagues, ${ }^{3}$ the authors use descending aortic perfusion and maintenance of whole-body perfusion, removing the need for lowerbody circulatory arrest and hypothermia. This technique of cannulating the descending aorta has been described before, initially by Yasui and colleagues ${ }^{4}$ in 1993 and then further refined by other groups. Descending aortic perfusion has the advantage of not requiring deep hypothermia, as the entire operation can be done with continuous perfusion. This may translate into less acute kidney injury and more rapid postoperative progress. Provided the ascending and descending cannula sizes are the same, then the distribution of the flow to the lower body will be determined by the peripheral vascular resistance and similar to ordinary cardiopulmonary bypass flow without cross clamping. Operation for circumflex aorta is an ideal application of this approach and is best done as a young infant whilst the aorta maintains maximal elasticity to ease mobilization.

\footnotetext{
From the Division of Cardiothoracic Surgery, Heart Institute, Cincinnati Children's Hospital Medical Center, Cincinnati, Ohio.

Disclosures: The authors reported no conflicts of interest.

The Journal policy requires editors and reviewers to disclose conflicts of interest and to decline handling or reviewing manuscripts for which they may have a conflict of interest. The editors and reviewers of this article have no conflicts of interest.

Received for publication Oct 9, 2020; revisions received Oct 9, 2020; accepted for publication Oct 20, 2020; available ahead of print Oct 22, 2020.

Address for reprints: David Winlaw, MBBS, MD, FRACS, Cincinnati Children's Hospital Medical Center, 3333 Burnett Ave, MLC 2003, Cincinnati, OH 45229 (E-mail: david.winlaw@cchmc.org).

JTCVS Techniques 2020;4:243-4

2666-2507

Copyright (C) 2020 The Authors. Published by Elsevier Inc. on behalf of The American Association for Thoracic Surgery. This is an open access article under the CC BY-NCND license (http://creativecommons.org/licenses/by-nc-nd/4.0/).

https://doi.org/10.1016/j.xjtc.2020.10.029
}

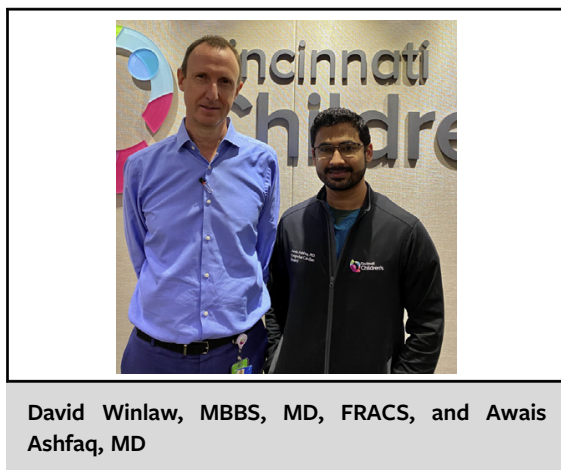

CENTRAL MESSAGE

Distal aortic perfusion allows correction of the circumflex aorta, maintaining full perfusion. Airway considerations are paramount.

In our experience of 2 similar cases, the aortic uncrossing procedure effectively reduced external airway compression, as pointed out by the authors, ${ }^{3}$ but the postoperative course was complicated by tracheobronchomalacia at the site of previous airway compression. Relief of extrinsic compression unmasks this tracheal pathology, and both patients required a period of postoperative noninvasive ventilation. Others have noted the utility of airway pexy to address the collapse of the deformed airway that often manifests after withdrawal of positive pressure ventilation. ${ }^{5}$ Recurrent laryngeal nerve palsy may further complicate recovery.

Preoperative computed tomography may not fully characterize functional impairment of the trachea related to airway collapse. It is, therefore, prudent to visualize the airway both before and after uncrossing surgery, particularly if weaning from ventilation is difficult. Residual tracheal deformity can then be addressed by pexy, external support, or resection. A dynamic postoperative study of the airway is required in those who fail to gain early and substantial benefit. Fortunately, the need for airway procedures to follow an aortic uncrossing operation is unusual, and most patients gain an excellent functional result by uncrossing alone.

\section{References}

1. Planché C, Lacour-Gayet F. Aortic uncrossing for compressive circumflex aorta: 3 cases. Presse Med. 1994;13:1331-2 [in French].

2. Russell HM, Rastatter JC, Backer CL. The aortic uncrossing procedure for circumflex aorta. Op Tech Thorac Cardiovasc Surg. 2013;18:15-31.

3. Said SM, Marey G, Jakubowski L, Miranda C. Aortic uncrossing procedure: when the right becomes left. J Thorac Cardiovasc Surg Tech. 2020;4:239-42. 
4. Yasui H, Kado H, Yonenaga K, Kawasaki S, Shiokawa Y, Kouno H, et al. Revised technique of cardiopulmonary bypass in one-stage repair of interrupted aortic arch complex. Ann Thorac Surg. 1993;55:1166-71.
5. Kamran A, Friedman KG, Jennings RW, Baird CW. Aortic uncrossing and tracheobronchopexy corrects tracheal compression and tracheobronchomalacia associated with circumflex aortic arch. J Thorac Cardiovasc Surg. 2020;160:796-804. 